\section{YOUR PRACTICE'S LEGIONELLA RISK}

HTM 01-04 and 01-05 state that all registered dental practices need to have undertaken a Legionella risk assessment and written scheme by April 2011. Specialist Legionella consultancy Building Monitoring Services (BMS) can help you comply with this requirement.

A Legionella risk assessment assesses the water systems within a property with regard to its ability to increase and spread Legionella bacteria which could infect patients and employees. A written scheme details what needs to be done to control the Legionella risk.

BMS are members of the Legionella Control Association, recommended by the HTM, and have created a bespoke, affordable service specifically designed for dental practices.

The specialist service includes a Legionella risk assessment for all water systems present; schematic drawings of systems; and a detailed report of any remedial work required and possible monitoring.

Reader response number 57

\section{ECO-FRIENDLY SUPER CLOTHS}

Evident has recently introduced a range of microfibre cloths called e-cloth Professional.

When these clever microfibre cloths are used with water they are just as effective as using harsh chemicals for removing infectious agents from surfaces in dental practices.

e-cloth Professional has 30,000 fibres per square inch and more than 500 million fibre strands per cloth. The special fibre is capable of entangling and thus removing a wide range of pathogenic particles from surfaces to which they otherwise stick. This means the cloth removes grease, dirt and bacteria from hard surfaces without the need for

\section{CHIC, MODERN, COMPLIANT}

Tavom uses the latest in Computer Aided Design (CAD) to help eliminate the stress of dental practice refurbishment.

The Alnair Range from Tavom combines stylish design with practicality and provides storage that maximises even the smallest of spaces. The range includes chic Y Glass work surfaces, making surgeries ultra modern environments to work in.

With over 30 years of experience, Tavom is well versed in all the latest decontamination protocols so that you can ensure your surgery complies with every decontamination regula- harsh, needlessly expensive cleaning products. In addition the cloth contains antibacterial nanosilver and has the added bonus of being eco-friendly: they can be washed up to 1,000 times before they need to be replaced.

e-cloth Professional is available in green, blue, red and yellow, so different colours can be used for different purposes. They are supplied in packs of ten of one colour.

HTM 01-05 suggests that, provided deep cleaning is performed as an initial exercise, the patient treatment area should be cleaned after every session using disposable cloths or clean microfibre materials.

Reader response number 58

tion. Providing high quality, durable, aesthetically pleasing, hygienic dental cabinetry and furniture, Tavom can assist you in creating a highly professional and functional practice to suit your needs.

Reader response number 59

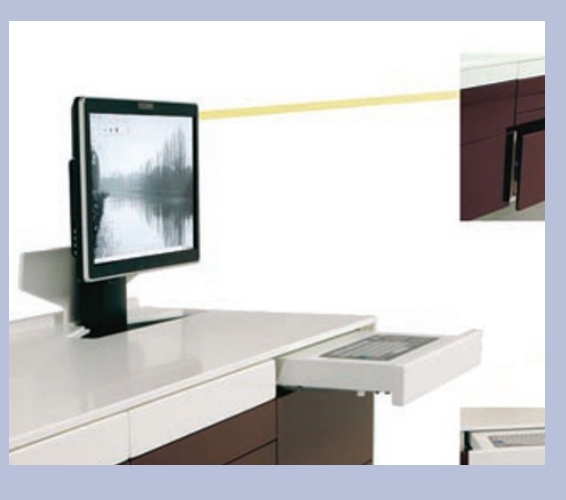

